\title{
CAMINHOS DO RIO XINGU: POVOS, PAISAGENS E BELEZAS NATURAIS NO MÉDIO XINGU
}

Dilma Costa Ferreira $ه$

Universidade Federal do Pará I Belém - PA - Brasil 


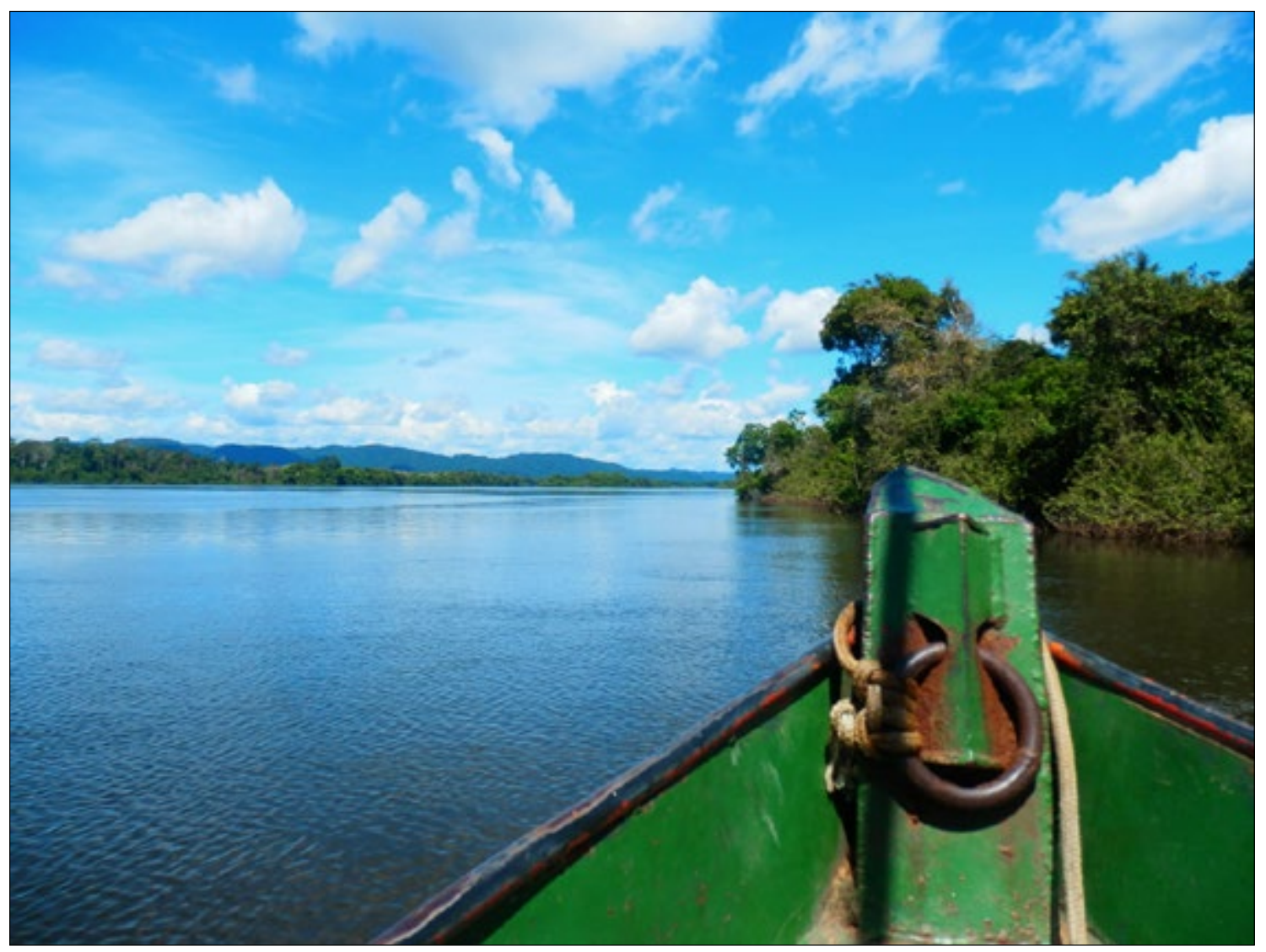

Figura 2 - Beleza em águas do rio Xingu. Foto: Dilma Ferreira (2014).

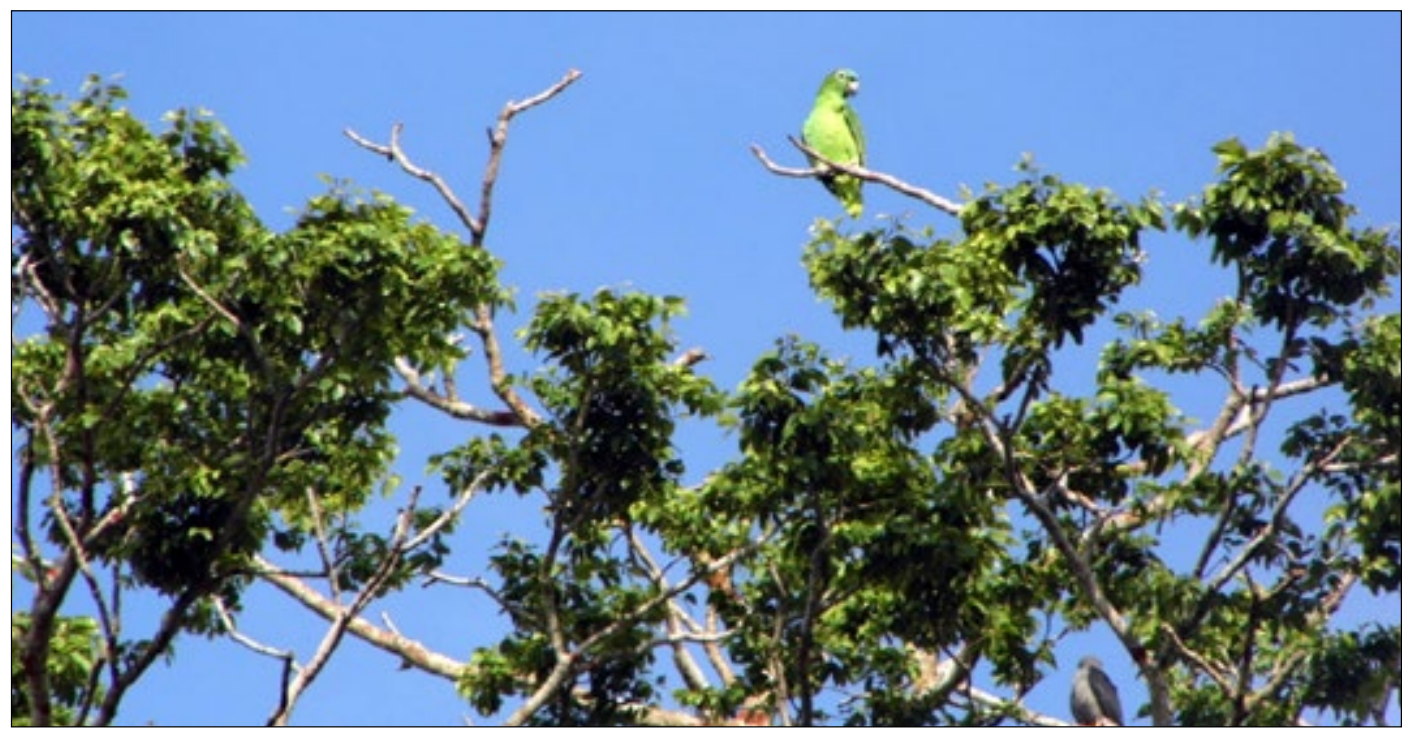

Figura 3 - Um espetáculo de flora e fauna às margens do rio Xingu, que alimenta o corpo e a alma dos povos que vivenciam essa beleza natural. Foto: Dilma Ferreira (2013). 


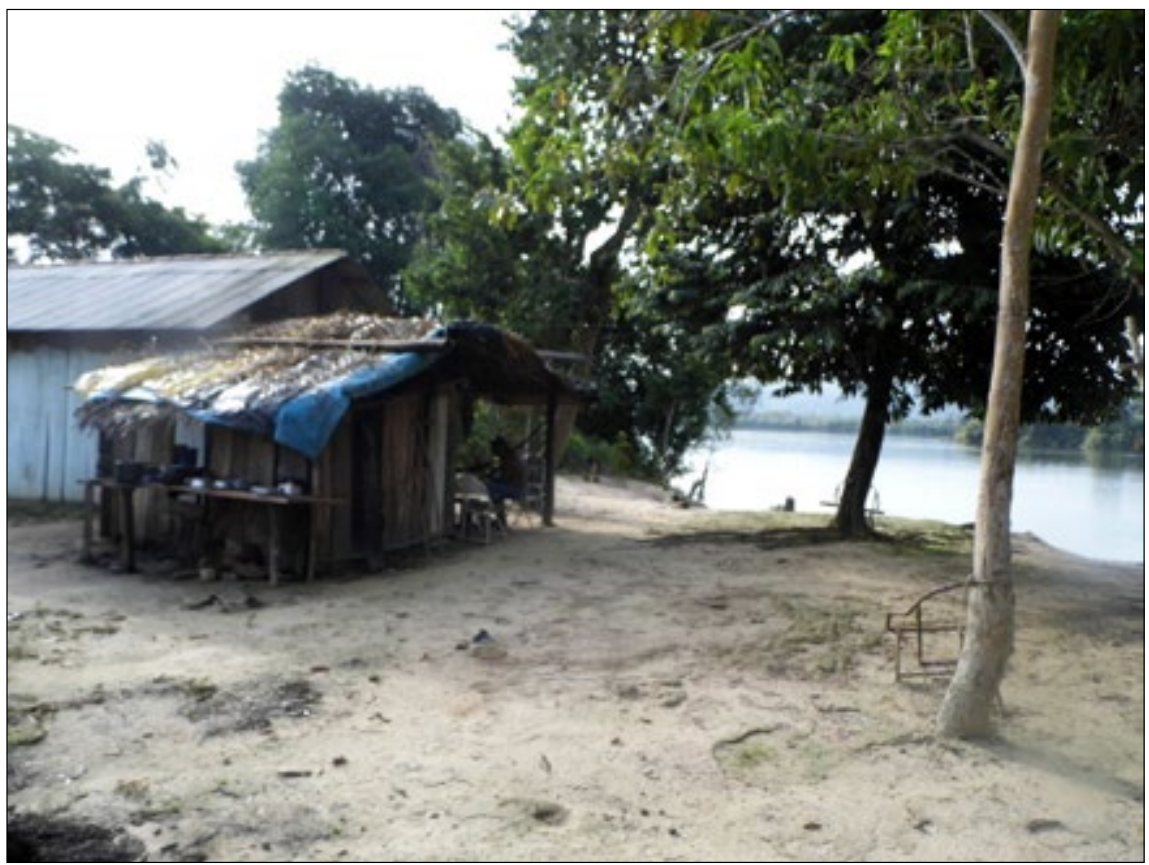

Figura 4 - Casa de ribeirinho às margens do rio Xingu, no médio Xingu. Foto: Dilma Ferreira (2013).

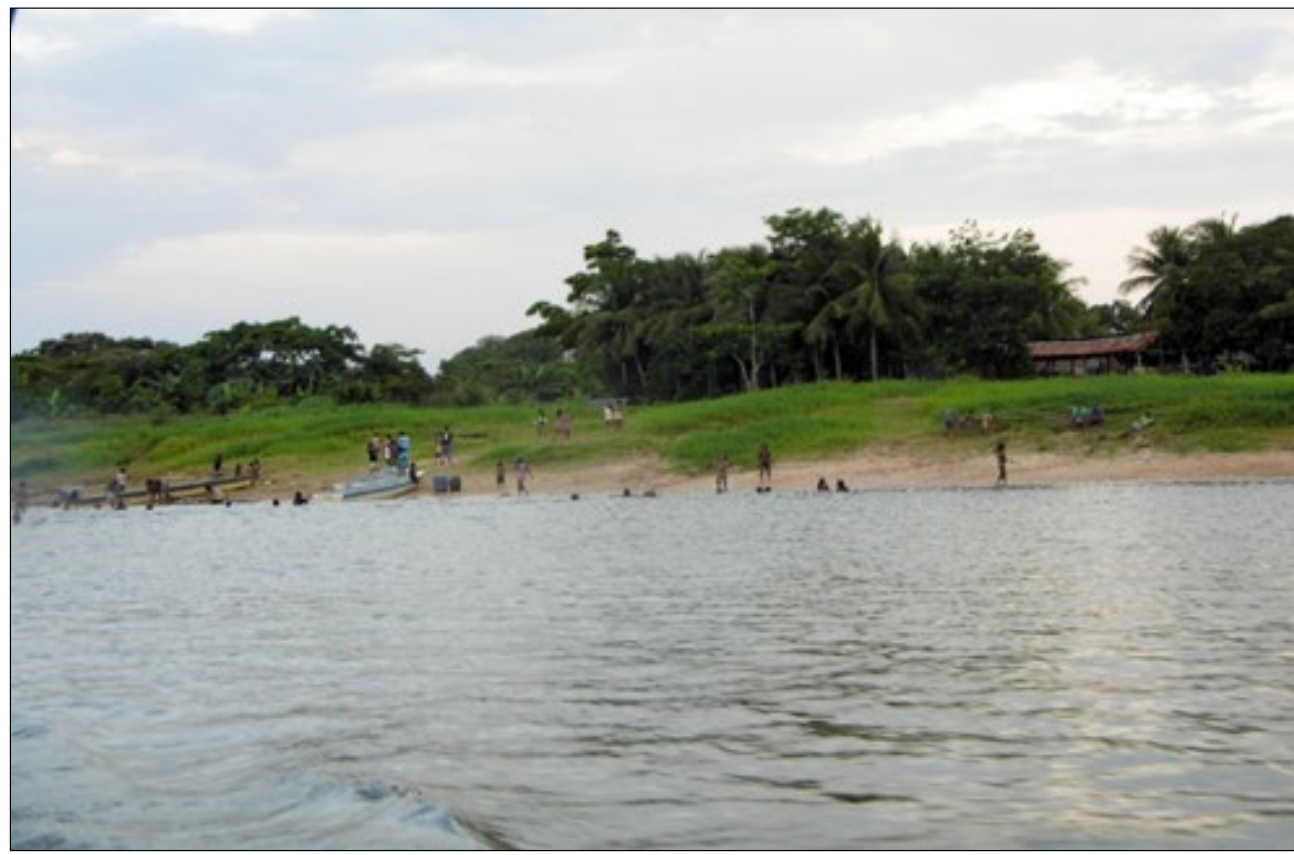

Figura 5 - Aldeia Kokrajmoro, uma das mais antigas do povo Mẽbêngôkre, às margens do rio Xingu, localizada no município de São Félix do Xingu, estado do Pará, com aproximadamente 800 habitantes. Desde 1980, este espaço vem sendo palco de diversas cisões, prática comum entre os povos Jê, as quais possibilitaram a criação de várias aldeias nos arredores do rio Xingu e região, entre elas Pykararankre, Rikaro e Tepdjàti. Foto: Dilma Ferreira (2013). 


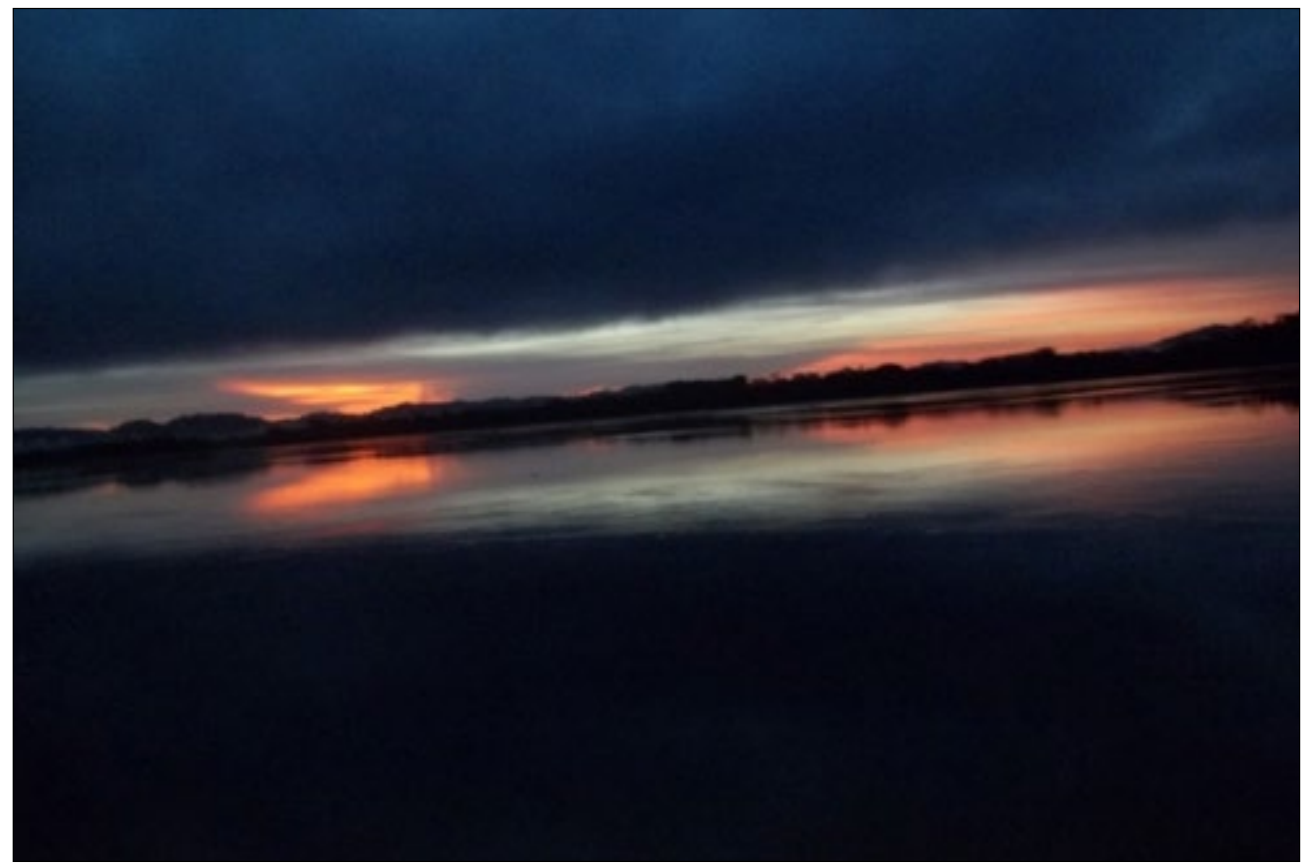

Figura 6 - Despertar pela “Aurora dos dedos Roséos”. Um espetáculo de cores e sensibilidades. Foto: Dilma Ferreira (2013).

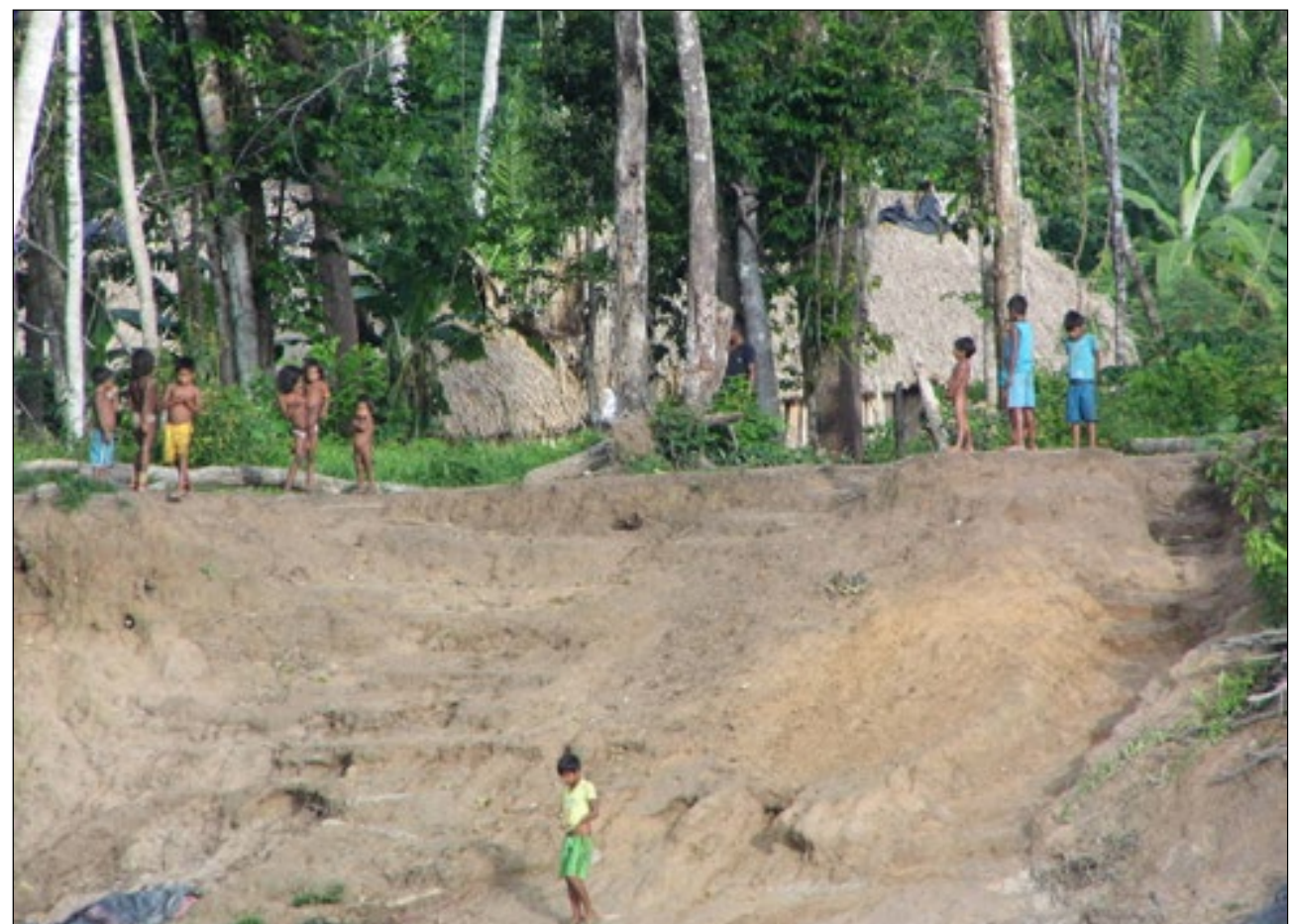

Figura 7 - O cotidiano de crianças indígenas Mẽbêngôkre, ao amanhecer, às margens do rio Xingu. Foto: Dilma Ferreira (2013). 
volume 11 (2) | 859 - 871 | 2019

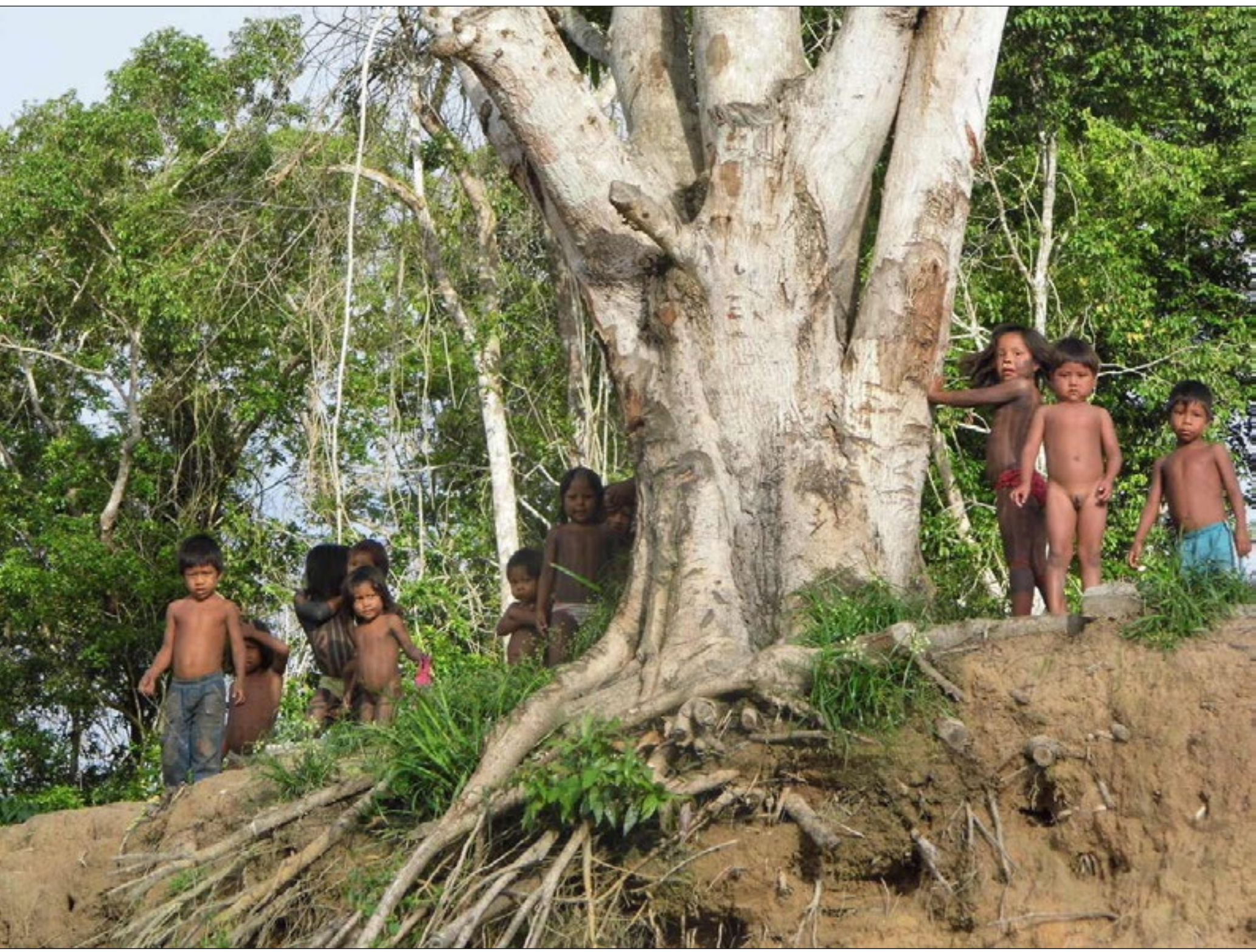

Figura 8 - O olhar curioso das crianças e a recepção rotineira dos Mẽbêngôkre. Foto: Dilma Ferreira (2013). 


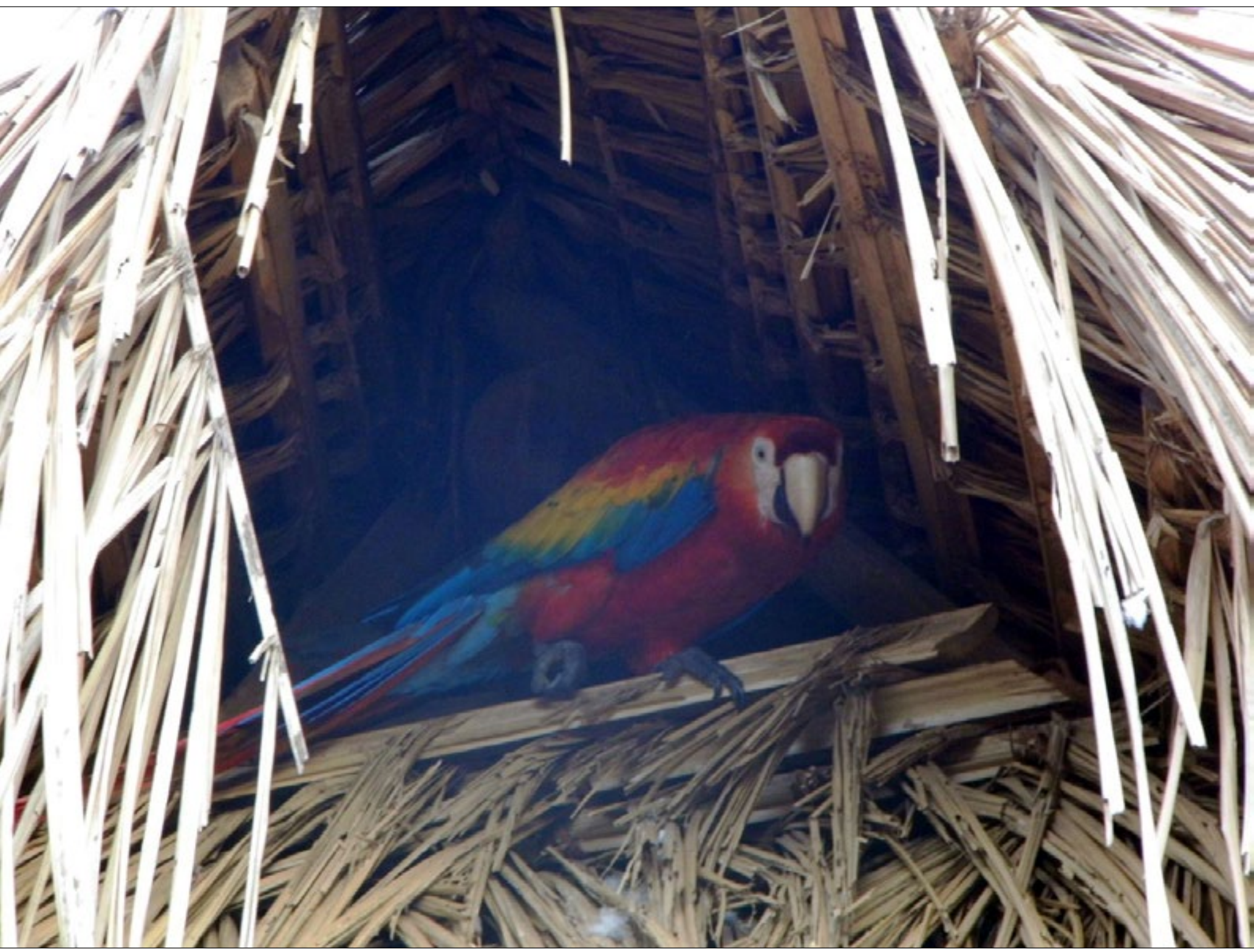

Figura 10 - Arara vermelha, um animal de estimação pertencente a uma casa Mẽbêngôkre. Foto: Dilma Ferreira (2013). 


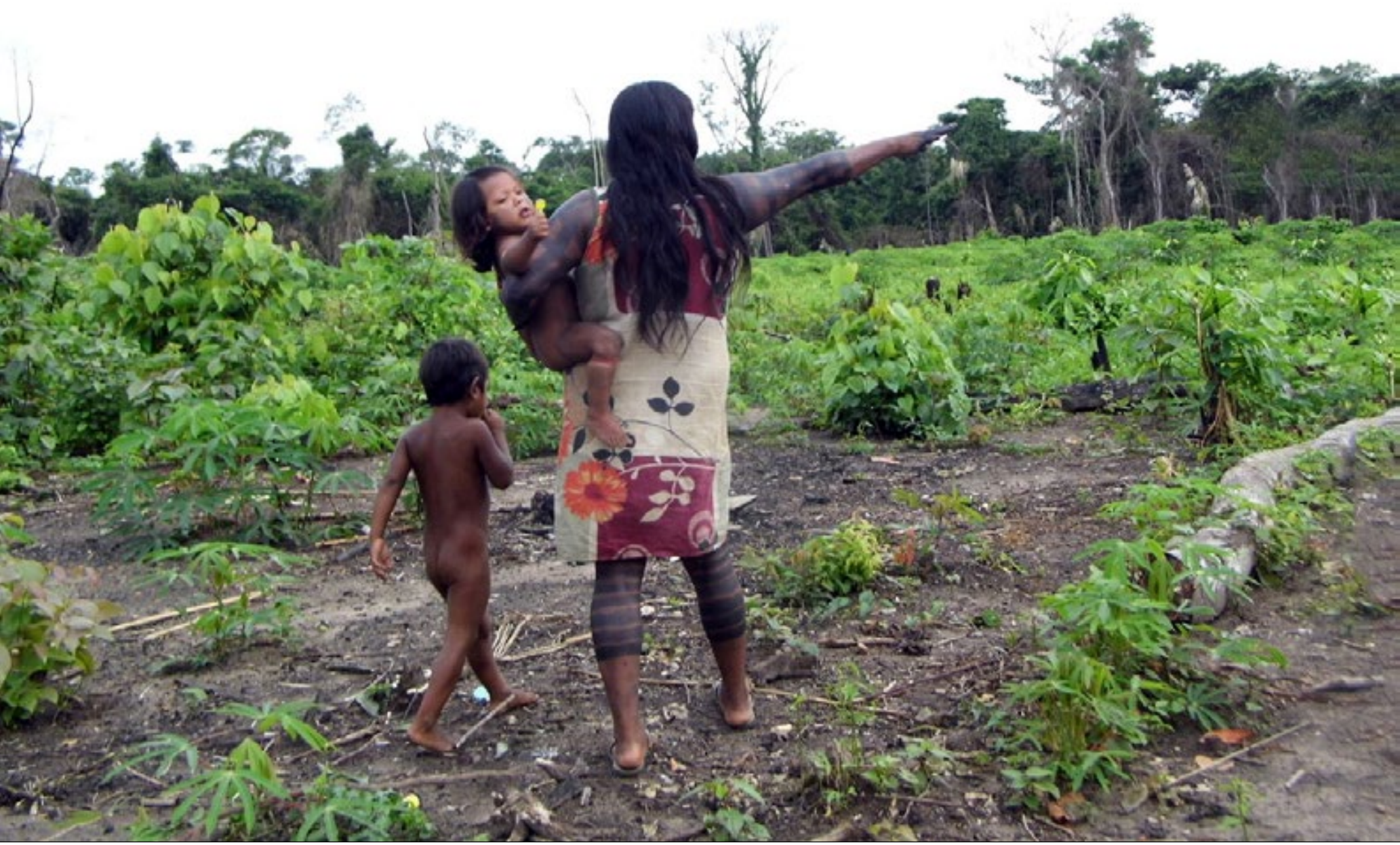

Figura 11 - Mulher Mẽbêngôkre mostrando a beleza das roças, ao lado de seus netos (tàbdjwy). Foto: Dilma Ferreira (2013). 
volume 11 (2) | 859 - 871 | 2019

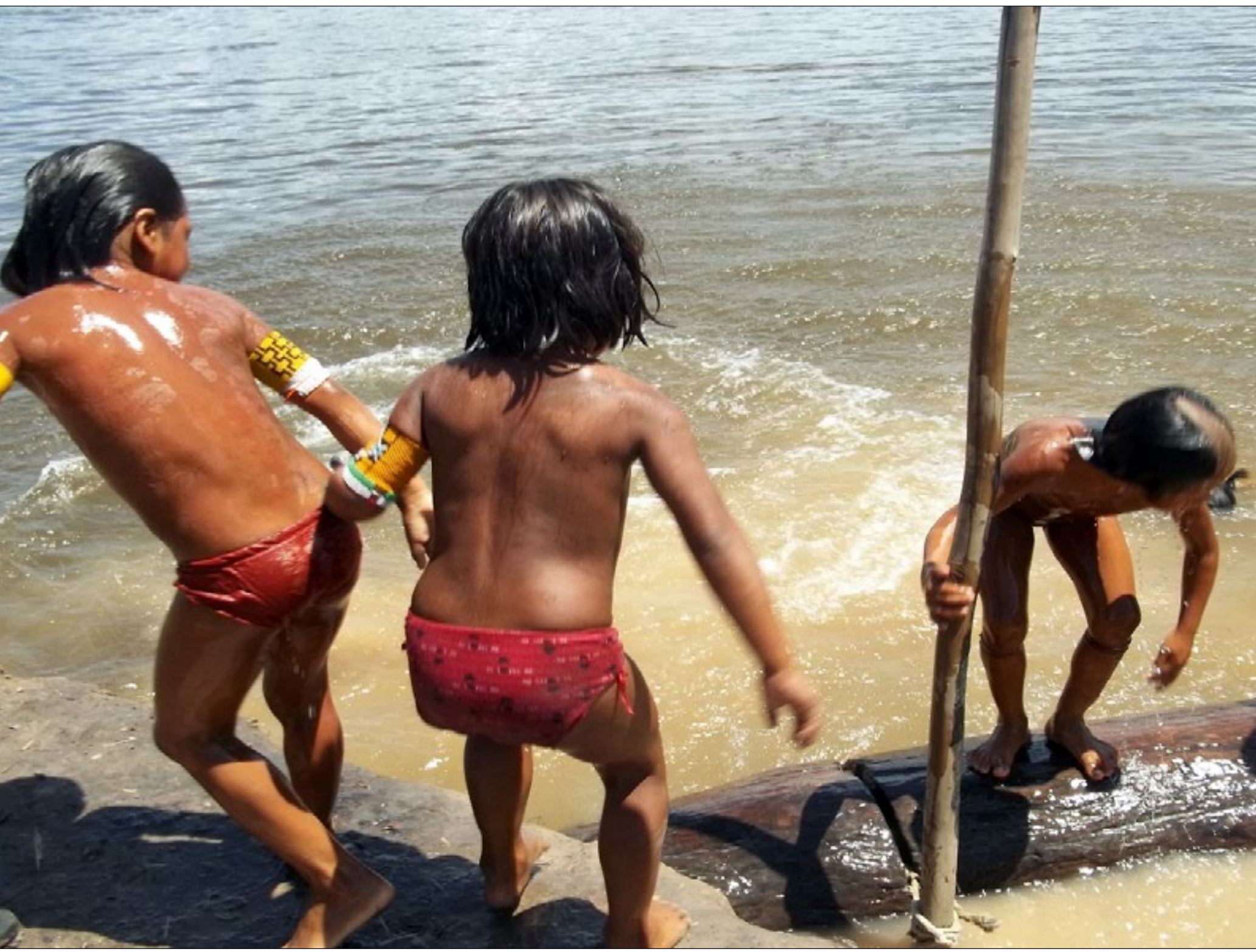

Figura 12 - Crianças Mẽbêngôkre brincando à margem do rio Xingu, porto da aldeia Rikaro. Foto: Dilma Ferreira (2014). 


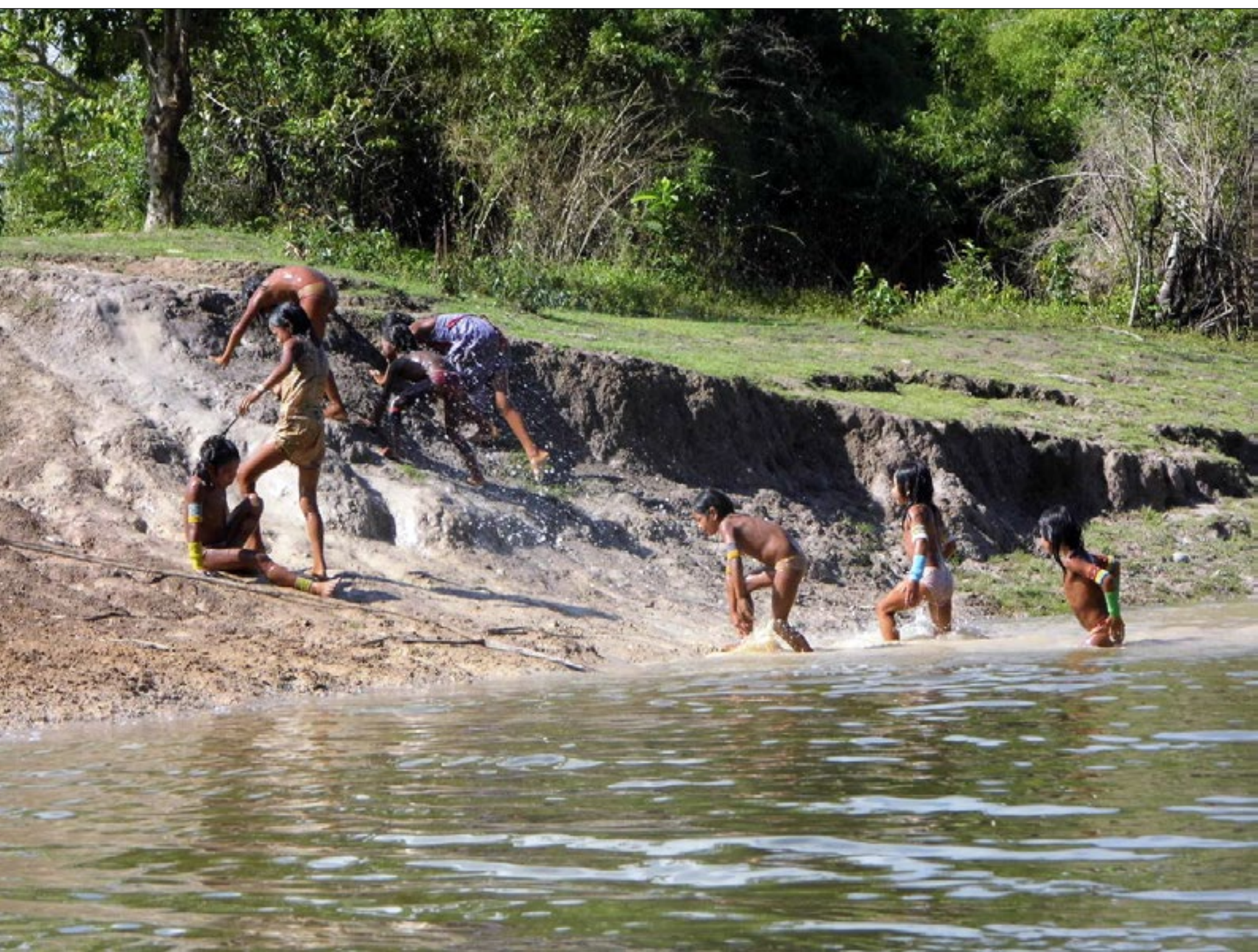

Figura 13 - Um pouco mais do cotidiano das crianças Mẽbêngôkre, brincando no porto da aldeia Pykararãnkre. Foto: Dilma Ferreira (2014). 


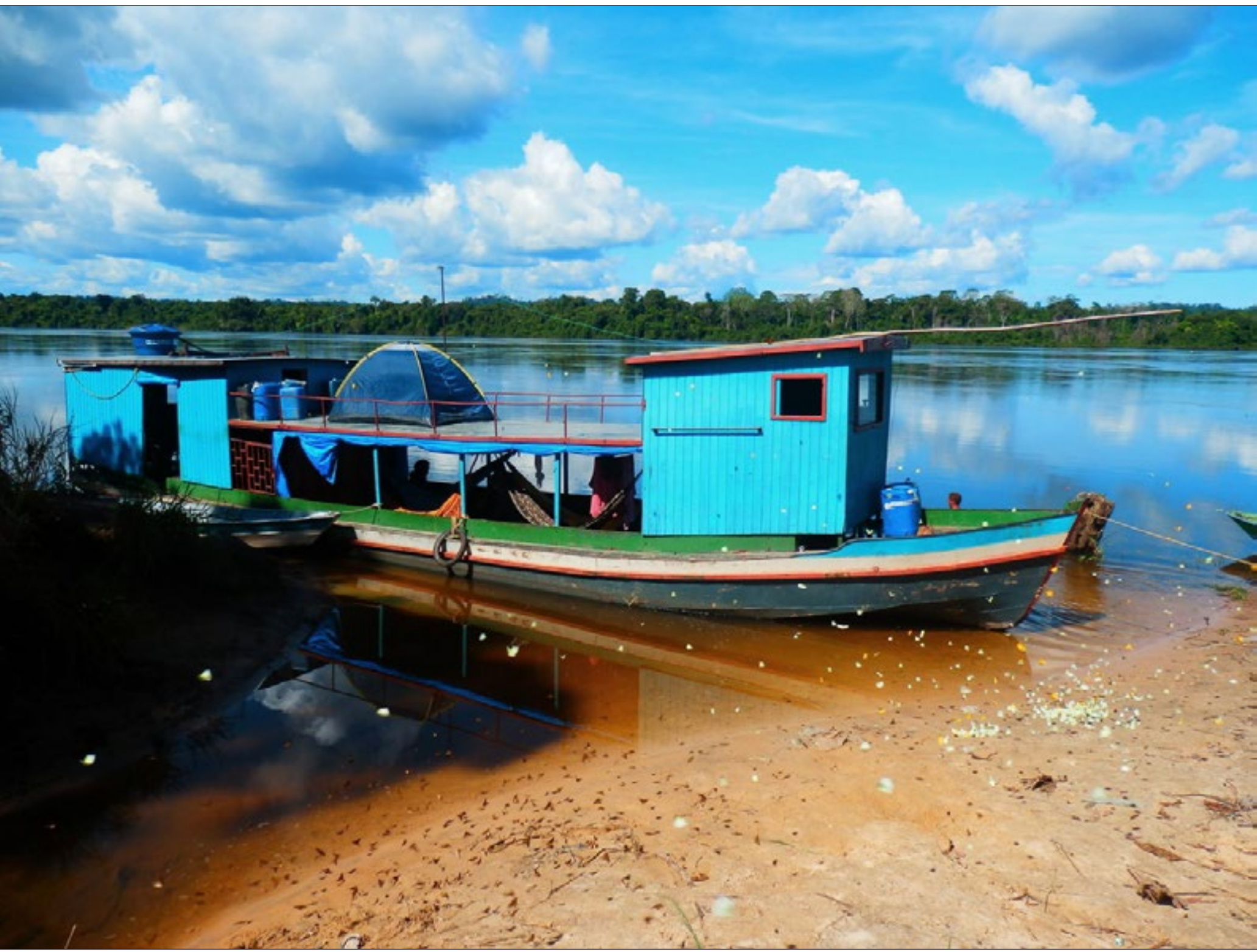

Figura 15 - Chegando ao final da trajetória, um lindo revoar de borboletas, contemplado no médio Xingu. Foto: Dilma Ferreira (2014). 